\title{
Microtubule destabilization caused by silicate via HDAC6 activation contributes to autophagic dysfunction in bone mesenchymal stem cells
}

\author{
Zheng $\mathrm{Li}^{\dagger}$, Shuhao Liư ${ }^{\dagger}$ Tengfei $\mathrm{Fu}^{\dagger}$, Yi Peng and Jian Zhang ${ }^{*}$ (1)
}

\begin{abstract}
Background: Silicon-modified biomaterials have been extensively studied in bone tissue engineering. In recent years, the toxicity of silicon-doped biomaterials has gradually attracted attention but requires further elucidation. This study was designed to explore whether high-dose silicate can induce a cytotoxicity effect in bone mesenchymal stem cells (BMSCs) and the role of autophagy in its cytotoxicity and mechanism.

Methods: Morphologic changes and cell viability of BMSCs were detected after different doses of silicate exposure. Autophagic proteins (LC3, p62), LC3 turnover assay, and RFP-GFP-LC3 assay were applied to detect the changes of autophagic flux following silicate treatment. Furthermore, to identify the potential mechanism of autophagic dysfunction, we tested the acetyl-a-tubulin protein level and histone deacetylase 6 (HDAC6) activity after high-dose silicate exposure as well as the changes in microtubule and autophagic activity after HDAC6 siRNA was applied.

Results: It was found that a high dose of silicate could induce a decrease in cell viability; LC3-II and p62 simultaneously increased after high-dose silicate exposure. A high concentration of silicate could induce autophagic dysfunction and cause autophagosomes to accumulate via microtubule destabilization. Results showed that acetyla-tubulin decreased significantly with high-dose silicate treatment, and inhibition of HDAC6 activity can restore microtubule structure and autophagic flux.

Conclusions: Microtubule destabilization caused by a high concentration of silicate via HDAC6 activation contributed to autophagic dysfunction in BMSCs, and inhibition of HDAC6 exerted a cytoprotection effect through restoration of the microtubule structure and autophagic flux.
\end{abstract}

Keywords: BMSCs, Silicate, Autophagic flux, Microtubule, HDAC6

\section{Background}

Bone mesenchymal stem cells (BMSCs), which are derived from the bone marrow, have the capacity for multidirectional differentiation within special culture conditions $[1,2]$. BMSCs play an important role in the process of bone growth, development, and repair and are indispensable to bone formation. BMSCs act both as an important source of osteoblasts and in the synthesis and secretion of various growth factors [3]. Silicate-doped biomaterials can

\footnotetext{
*Correspondence: zhangjianzsyy@126.com

${ }^{\dagger}$ Zheng Li, Shuhao Liu and Tengfei Fu contributed equally to this work. Department of Orthopaedics, Zhongshan Hospital of Fudan University, 180 Fenglin Road, Shanghai, China
}

induce the differentiation of BMSCs and enhance bone formation in a certain range [4-6]. In recent years, the cytotoxicity of silicate-doped biomaterials has gradually attracted attention, and studies have found that silicatedoped bioceramics could promote the caspase-dependent apoptosis of macrophages via altering the ionic microenvironment between the implants and hosts [7]. In clinical practice, it was found that primary total hip arthroplasty (THA) using bioactive bone cement $\left(\mathrm{SiO}_{2}\right.$ $34.0 \%$ ) showed an early radiological loosening after longterm follow-up, and the mechanism still remained unclear [8]; several researches identified that intracortical silicon microelectrode implants could cause blood-cerebral 
barrier dysfunction and neuronal cell loss [9, 10]. Moreover, studies have confirmed that a high concentration of silicate could inhibit the viability of human BMSCs [11]. Our previous study also identified that a high concentration of silicate could induce autophagic flux blockage and cellular apoptosis in human umbilical vein endothelial cells [12]. However, whether silicate has a cytotoxic effect on BMSCs and its mechanism remains to be further studied. Furthermore, silicon ion concentrations in different biomaterials range from $0.03 \mathrm{mM}$ at the lowest up to 50 $\mathrm{mM}$ at the highest [13]. Silicon is a trace element in the human body, and the silicon content of most implants is significantly higher than the normal range of the human body; the potential toxicity of silicate cannot be ignored, and its logical range in BMSCs still needs further identification $[13,14]$.

Autophagy is a functionally and evolutionarily preserved process that degrades and recycles harmful proteins or injured organelles in eukaryotic cells [15]. Autophagy broadly includes macroautophagy, microautophagy, and chaperone-mediated autophagy. This study mainly focuses on macroautophagy, which is also the most studied. Autophagy is an adaptive response to maintain cell homeostasis and survival in the face of adverse environmental threats or stress. Disruption of autophagy can induce cells to self-repair disorders and further fall into apoptosis or necrosis $[16,17]$. Moreover, Yang et al. have found that activation of autophagy could partially reverse the aging of BMSCs and increase osteogenic differentiation capacity; furthermore, autophagy could maintain the osteogenic differentiation ability of mesenchymal stem cells under adverse conditions $[18,19]$.

At present, there is no systematic report on the effect of soluble silicate on autophagy. Although some studies have pointed out that silicon nanoparticles can block autophagy flux by affecting the lysosome function, it is almost always caused by the structure of the nanomaterials themselves [20-22]. Whether autophagy is related to silicon ions remains to be further studied. Here, based on the treatment of BMSCs with different concentrations of sodium metasilicate representing silicon ions, the effect of free silicate on autophagy was determined through the detection of autophagy flux. Simultaneously, a reference was provided to clarify the reasonable and safe range of silicon ions in BMSC-related biomaterials.

\section{Methods}

\section{Reagents and antibodies}

Chloroquine (CQ) was purchased from Sigma-Aldrich (St. Louis, MO, USA). Bafilomycin A1 (Baf A1) was purchased from Santa Cruz Biotechnology (Santa Cruz, CA, USA). Cell Counting Kit-8 (CCK-8) was purchased from Dojindo Molecular Technologies (Shanghai, China). LC3 (\#3868), HDAC6 (\#7612), acetyl- $\alpha$-tubulin (\#5335), and $\alpha$-tubulin (\#2125) primary antibodies were purchased from Cell Signaling Technology (Danvers, MA, USA). SQSTM1/p62 (\#ab56416), LAMP1 (\#ab24170), and LAMP2 (\#ab13524) primary antibodies were purchased from Abcam (Cambridge, UK). GAPDH (\#60004-1-lg), VAMP8 (\#15546-1-AP), SNAP29 (\#12704-1-AP), and STX17 (\#17815-1-AP) primary antibodies were purchased from Proteintech Group (Boston, MA, USA). The second antibodies (peroxidase-conjugated goat antirabbit IgG and peroxidase-conjugated goat anti-mouse IgG) were purchased from Yeasen Biotechnology (Shanghai, China). The sodium metasilicate solution was prepared as previously reported at a stock solution of high concentration $(100 \mathrm{mM})$ with some modification [23, 24]. In brief, sodium metasilicate solution (SigmaAldrich, \#338443) was diluted into alpha-MEM to prepare a stock solution. The $\mathrm{pH}$ was adjusted using $\mathrm{HCl}$ to a physiological range ( $\mathrm{pH}$ about 7.4) before $10 \%$ fetal bovine serum (FBS; ScienCell, Carlsbad, CA, USA) was added.

\section{Cell culture and treatment}

BMSCs were harvested and identified according to our previous studies [25]. In brief, the cells were extracted from the bone marrow of rats less than a month old and were identified with cell surface marker such as CD73, CD90, and CD105 as well as multilineage differentiation ability (osteogenesis, adipogenesis, and chondrogenesis). The cells were cultured and purified in alpha-MEM (Keygentec, Nanjing, China), which contained 10\% FBS and $1 \%$ penicillin/streptomycin solution $(\mathrm{P} / \mathrm{S})$, in an incubator at $37^{\circ} \mathrm{C}$ with $5 \% \mathrm{CO}_{2}$. Cell dissociation and passages were performed for 3 days each time. Primary BMSCs are prone to aging, and we generally only use the cells in four generations. The medium was replaced with different concentrations of chemicals when the cells achieved $80 \%$ density and continued to culture for $24 \mathrm{~h}$. Cells were pretreated with CQ or Baf A1 for $2 \mathrm{~h}$ and continued in the following $24 \mathrm{~h}$ in the corresponding group.

\section{ICP-AES}

Inductively coupled plasma atomic emission spectrometry (ICP-AES, NexION 300X ICP-MS, PerkinElmer, Waltham, MA, USA) was applied to evaluate the cellular silicon level. BMSCs were treated with various concentrations $(0,0.1,0.5,1.5 \mathrm{mM})$ of silicate for $24 \mathrm{~h}$. Cell samples were collected and washed with phosphatebuffered saline (PBS) twice and subsequently resuspended in PBS for cell counting. After that, the cells were centrifuged and lysed with $5 \mathrm{ml}$ RIPA overnight at room temperature. The silicon standard series was prepared, and the silicon level in the samples was measured by ICP-AES. The results are presented as the silicon level in each $10^{6}$ cells (umol $/ 10^{6}$ cells). 


\section{Cell viability}

Morphologic changes in BMSCs under the microscope $(\times 40)$ were recorded and compared after being treated with different concentrations of silicate $(0,0.1,0.5,1.5$, 3, $5 \mathrm{mM}$ ). CCK-8 was used to evaluate cell viability at different time points $(6 \mathrm{~h}, 24 \mathrm{~h}, 72 \mathrm{~h})$. In brief, BMSCs were cultured in a 96-well plate with a density of $1 \times$ $10^{5}$, and they were treated with different concentrations of silicate $(0.1,0.5,1.5,3,5 \mathrm{mM})$. When the cells achieved $80 \%$ density, each group was set with 6 repeat wells. To each well, $10 \mu \mathrm{l}$ of CCK- 8 was added and cells were incubated at $37^{\circ} \mathrm{C}$ for $2 \mathrm{~h}$. The absorbance values were measured at a $460-\mathrm{nm}$ wavelength with a spectrophotometer. The viability rate was calculated using the following formula:

Viability rate $(\%)=(\mathrm{OD}$ treatment group - OD blank group) / (OD control group - OD blank group) $\times 100 \%$

\section{Western blot analysis}

Western blot was conducted as reported previously [12, 25]. In brief, RIPA with protease inhibitor (PMSF) was applied to lyse BMSCs on ice. A total of $30 \mu \mathrm{g}$ protein was loaded and separated with $12.5 \%$ sodium dodecyl sulfate-polyacrylamide gel electrophoresis (12.5\%; Epizyme Biotech, Shanghai, China) and then transferred to a polyvinylidene fluoride membrane $(0.2 \mu \mathrm{m}$; Millipore, Darmstadt, Germany). The membrane was blocked with $5 \%$ nonfat milk for $1 \mathrm{~h}$ at room temperature and incubated with primary antibodies at $4{ }^{\circ} \mathrm{C}$ for the night. Primary antibodies, including LC3, p62, HDAC6, acetyl- $\alpha$-tubulin, $\alpha$-tubulin, VAMP8, SNAP29, and STX17, were diluted at 1:1000; LAMP1 and LAMP2 primary antibodies were diluted at 1:500; and GAPDH antibody was diluted at 1:5000. The secondary antibodies (HRPlinked rabbit or mouse at 1:3000 dilution) were applied at room temperature for $2 \mathrm{~h}$ after TBST washing. Enhanced chemiluminescence system reagent was applied for imaging exposure, and results of the images were analyzed by Quantity One software. The experiments were repeated at least four times for each protein.

\section{Immunofluorescence assay}

Immunofluorescence assay was performed as previously reported with some modifications [12]. For LC3 staining, the slide of the BMSCs was fixed in $4 \%$ paraformaldehyde for $10 \mathrm{~min}$ and subsequently permeabilized in $0.25 \%$ Triton X-100 for 15 min. After that, the slide was blocked with $3 \%$ bovine serum albumin for $30 \mathrm{~min}$ at room temperature and then incubated with rabbit antiLC3 primary antibody (1:200, Cell Signaling Technology) overnight at $4{ }^{\circ} \mathrm{C}$. Then, the cell slice was incubated in FITC-AffiniPure Goat Anti-Rabbit IgG (1:50, Yeasen Biotechnology, Shanghai, China) for $1 \mathrm{~h}$ at room temperature and subsequently with DAPI for $5 \mathrm{~min}$. The slide was reviewed and recorded under a fluorescence microscope (Nikon, Tokyo, Japan). LC3 puncta indicated autophagosomes; the number of LC3 puncta was counted and compared in 30 random fields $(\times 400)$, and the data were presented as LC3 dots count/cell. Moreover, specific BMSCs with stable expression of the mRFP-GFP-LC3 were constructed; BMSCs were inoculated with Ad-mRFP-GFP-LC3 (\#HB-AP210, Hanbio, Shanghai, China) for $48 \mathrm{~h}$ and then treated with corresponding reagents. The samples were reviewed and recorded under a fluorescence microscope. For the lysotracker, BMSCs were cultured in a 12-well plate and divided into the following groups: control group, silicate (3 mM)-treated group, Baf A1 (100 nM) or CQ (20 uM) group. Lyso-tracker solution (Keygentec, Nanjing, China) was diluted in alpha-MEM at 1:500 and co-cultured with BMSCs at $37^{\circ} \mathrm{C}$ for $30 \mathrm{~min}$. The slide was reviewed and recorded under a fluorescence microscope (Nikon, Tokyo, Japan). The fluorescence intensity was evaluated and analyzed using ImageJ software in 30 random cells, and the average fluorescence intensity per cell was compared. For the tubulin-tracker assay, BMSCs were cultured in slides and treated with different concentrations of silicate or interference for $24 \mathrm{~h}$ in the corresponding group. The slide of BMSCs was fixed in 4\% paraformaldehyde for $10 \mathrm{~min}$ and subsequently washed twice in $0.1 \%$ Triton X-100 for $5 \mathrm{~min}$. The tubulin-tracker solution (Keygentec, Nanjing, China) was diluted in alphaMEM in 1:200 and co-cultured with BMSCs at $37^{\circ} \mathrm{C}$ for $1 \mathrm{~h}$. The slide was reviewed and compared via laser scanning confocal microscopy (Leica, Wetzlar, Germany).

\section{Real-time quantitative polymerase chain reaction}

Total RNA from treated cells was extracted via RNA Extraction Reagent (Yeasen Biotech, Shanghai, China) according to the manufacturer's instructions. The concentration and quality of RNA were evaluated by spectrophotometric determination at $260 / 280 \mathrm{~nm}$, and equal amounts of RNA from each sample were used for cDNA reverse-transcription following the PrimeScript RT Reagent Kit with gDNA Eraser (Takara Biomedical Technology, Beijing, China). cDNA was further applied as a template for real-time quantitative polymerase chain reaction (RT-qPCR) following the manufacturer's instructions (Mastercycler Gradient, Eppendorf, Germany). The primers were listed as follows:

Syntaxin 17 (STX17): 5' -GAGGGTCCGTCAGTCAAG TT-3' (forward), 5' -CTGACCCTCAGGCATCCAAT-3' (reverse)

Synaptosome associated protein 29 (Snap29): 5'-CCCTTC CTGCTTCCAAGGTT-3' (forward), 5'-CCCTGCGTAA CACCTCTTGT-3' (reverse)

Vesicle-associated membrane protein 8 (Vamp8): 5'-GGAA GCCACGTCTGAACACTT-3' (forward), 5'-GATGGT GCCCGTAGCAAAGA-3' (reverse). 


\section{HDAC6 activity assay}

HDAC6 activity assay was conducted according to the manufacturer's instructions (\# 50076, BPS Bioscience, San Diego, CA USA). In brief, cell lysates of BMSCs were diluted in an HDAC assay buffer and subsequently mixed with the substrate. After that, a HDAC developer was added and the cell lysates continued to incubate. The values were measured with a spectrofluorometer with excitation at a wavelength of $380 \mathrm{~nm}$ and detection of emitted light of $460 \mathrm{~nm}$.

\section{SiRNA transfection}

The cells of each group were inoculated in 6-well plates 1 day before transfection. Alpha-MEM free of antibiotics was used for transfection dilution. The primer sequence of siRNA-HDAC6 (siHDAC6, RiboBio Co. Guangzhou, China) was designed as follows:

Sense: 5' -GCCGUAUUAUUCUUAUUCUdTdT-3'

Antisense: 5' -AGAAUAAGAAUAAUACGGCdTdT-3'

SiHDAC6 and its negative control sequences were mixed with Lipofectamine 2000 (Invitrogen, Carlsbad, CA, USA) according to the manufacturer's instructions. Following a 20-min incubation at $37^{\circ} \mathrm{C}$, the mixture was added to plates and continued to culture for 4-6 h and then used in subsequent experiments (nsRNA: vehicle group and silicate group ( $3 \mathrm{mM}$ ); SiHDAC6: vehicle group and silicate group $(3 \mathrm{mM}))$. The transfection efficiency was calculated according to the mRNA expression of HDAC6 after the cells were treated with $50 \mathrm{nM}$ siRNA for $48 \mathrm{~h}$.

\section{Statistical analysis}

Data are presented as mean \pm standard deviation (SD) and analyzed with GraphPad Prism 5.0 software (San Diego, CA, USA) or SPSS 20.0 (IBM Corp., Armonk, NY, USA). Multigroup comparisons of the means were carried out by one-way analysis of variance (ANOVA) test with post-test and by Student-Newman-Keuls (S$\mathrm{N}-\mathrm{K})$ multiple comparison test, and $p<0.05$ indicated statistical significance.

\section{Results}

High concentration of silicate affected morphologic changes and cell viability of BMSCs

Figure 1a displays the morphologic changes $(\times 40)$ of BMSCs after treatment with different concentrations of sodium metasilicate $(0,0.1,0.5,1.5,3,5 \mathrm{mM})$. As the concentration of sodium metasilicate increased, the number of suspended and deactivated cells increased. CCK-8 was applied to detect cell viability $(n=6)$ after treatment with different concentrations $(0,0.1,0.5,1.5$, $3,5 \mathrm{mM})$ of silicate at different time points $(6 \mathrm{~h}, 24 \mathrm{~h}, 72$ h). As we found, the cell viability decreased significantly after $3 \mathrm{mM}$ silicate $(0.80 \pm 0.07)$ exposure for $6 \mathrm{~h}$ compared with that of the control group $(1.01 \pm 0.07)$ (Additional file $1 \mathrm{a}$ ). After the 24-h silicate treatment, the cell viability in the group treated with $1.5 \mathrm{mM}(0.81 \pm 0.04)$ was lower than that of the control group $(0.99 \pm 0.04$, $p<0.01)$. The value continued to decrease as the concentration of sodium metasilicate increased $(p<0.001)$;
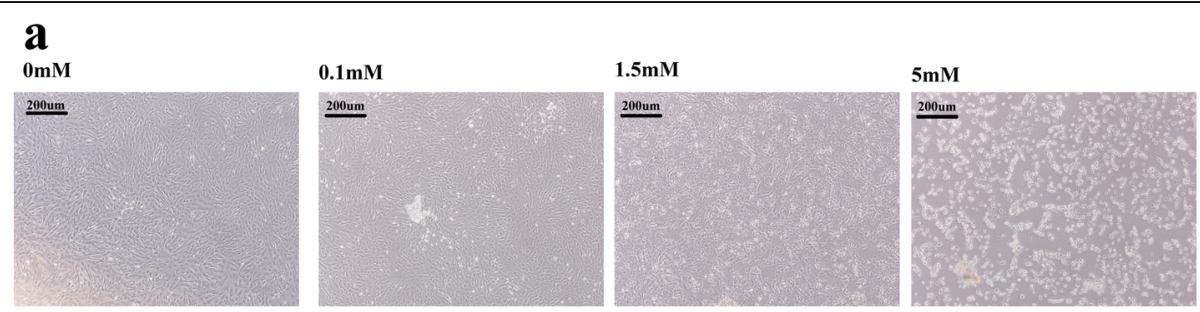

b

BMSC

c
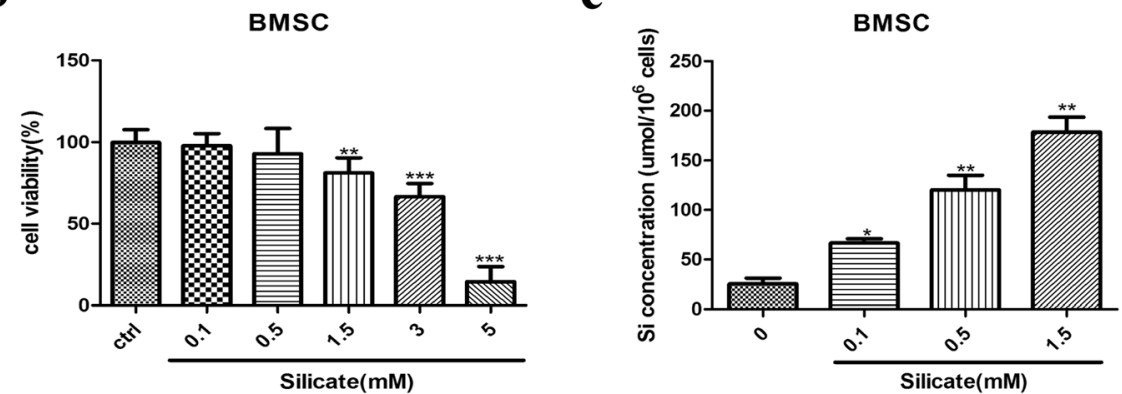

Fig. 1 High concentration of silicate affected morphologic changes and cell viability of BMSCs. a Morphologic changes $(\times 40)$ of BMSCs after treatment with different concentrations of sodium metasilicate $(0,0.1,1.5$, and $5 \mathrm{mM})$. As silicate concentrations increased, the number of suspended and deactivated cells increased. b CCK-8 was applied to detect cell viability $(n=6)$ after treatment with different concentrations $(0,0.1$, $0.5,1.5,3,5 \mathrm{mM}$ ) of silicate. Cell viability decreased significantly in groups treated with greater than $1.5 \mathrm{mM}$ silicate compared with that in the control group. c Intracellular silicon concentration increased with extracellular concentration $(n=4) .\left({ }^{*} p<0.05,{ }^{* *} p<0.01,{ }^{* * *} p<0.001\right)$ 
especially in the $5 \mathrm{mM}$ group $(0.14 \pm 0.04)$, most cells lost their viability under a high concentration of silicon, whereas in the $0.1 \mathrm{mM}$ group $(0.98 \pm 0.03)$ and $0.5 \mathrm{mM}$ group $(0.93 \pm 0.07)$, cell viability showed no significant difference compared with that of the control group. After the 72-h silicate exposure, the cell viability in the group treated with $1.5 \mathrm{mM}$ silicate further decreased $(0.40 \pm 0.05)$, while the cell viability still showed no significant change in the $0.1 \mathrm{mM}$ group $(1.03 \pm 0.08)$ and $0.5 \mathrm{mM}$ group $(0.97 \pm 0.06)$ (Additional file $1 \mathrm{~b})$. To further confirm whether low concentration of silicate ( $0.1 \mathrm{mM}$ and $0.5 \mathrm{mM})$ have cytotoxicity on BMSCs, the morphologic changes of BMSCs were recorded after 3 weeks of treatment with $0.1 \mathrm{mM}$ and $0.5 \mathrm{mM}$ silicate. Compared with the control group, the silicate did not show obvious cytotoxicity, the cells did not float or break as they did after treatment with high concentration of silicate, and some nodular changes can be observed during cell proliferation (arrow) (Additional file $2 \mathrm{a}-\mathrm{C}$ ). ICP-AES was used to detect the concentration of silicon inside the cells after treatment with different concentrations of silicate $(0,0.1,0.5,1.5 \mathrm{mM})$ for $24 \mathrm{~h}$. As shown in Fig. $1 \mathrm{c}$, the concentration of silicon inside the cells increased significantly with extracellular concentration.

\section{High concentration of silicate impaired autophagic flux in BMSCs}

The simultaneous increase in LC3-II and SQSTM1/p62 always indicated a blockage of autophagic flux. BMSCs were treated with different concentrations of silicate $(0$, $0.1,1.5,3 \mathrm{mM}$ ) for $24 \mathrm{~h}$, and Western blot was used to detect the protein expression of LC3-II and p62. As shown in Fig. 2a, b, data analysis demonstrated that LC3-II and p62 expression increased significantly $(p<$ 0.01 ) in the $1.5 \mathrm{mM}$ and $3 \mathrm{mM}$ groups compared with that of the control group. The immunofluorescence of LC3 (Fig. 2c) further confirmed that autophagosomes (LC3-positive dots) largely accumulated in BMSCs after treatment with $1.5 \mathrm{mM}$ or $3 \mathrm{mM}$ silicate, and data analysis (Fig. 2d) showed that the number of LC3 dots in the $1.5 \mathrm{mM}$ and $3 \mathrm{mM}$ groups significantly increased $(p<$ 0.001 ) compared with that of the control group. To further confirm the blockage of autophagic flux, an LC3 turnover assay was applied. Baf $\mathrm{A} 1$ and $\mathrm{CQ}$, which are classic

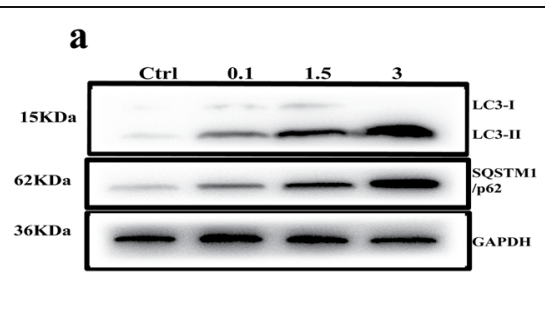

b

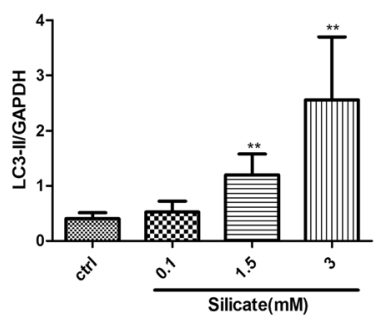

c

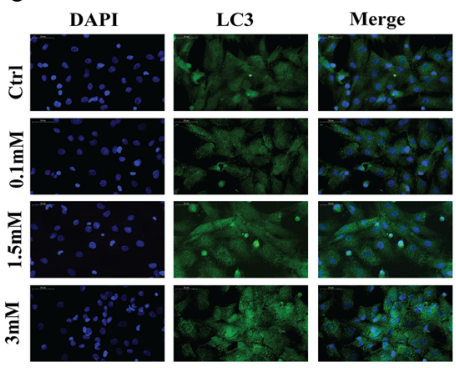

d
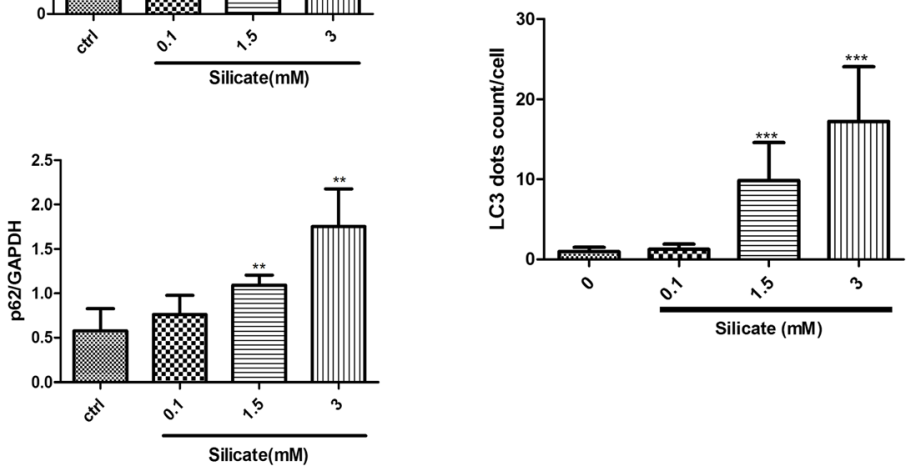

Fig. 2 Autophagosomes accumulated in high concentration of silicate-treated BMSCs. a, b Western blot showed the expression of LC3-II and p62 protein after silicate exposure for $24 \mathrm{~h}(n=4)$. LC3-II and p62 simultaneously increased significantly in groups treated with more than $1.5 \mathrm{mM}$ silicate as compared with that in the control group. c, d Autophagosomes were largely accumulated in BMSCs treated with greater than 1.5 mM silicate from LC3 fluorescence $\left(n=3,10\right.$ random fields per sample). $\left({ }^{* *} p<0.01,{ }^{* *} p<0.001\right)$ 
inhibitors of the autophagy pathway, were introduced to observe LC3 conversion. As shown in Fig. 3a, b, the protein expression of LC3-II and p62 was significantly increased $(p<0.01)$ after treatment with $1.5 \mathrm{mM}$ silicate compared with that of the control group; however, there was no significant difference in LC3-II and p62 expression after co-treatment with Baf A1 or CQ. Figure 3c displays the mRFP-GFP-LC3 expression after silicate exposure. Red dots indicate autolysosomes, while yellow dots indicate autophagosomes. As shown, autophagosomes were largely accumulated in BMSCs after exposure to $1.5 \mathrm{mM}$ silicate (yellow puncta), and the fusion of autophagosomes with lysosomes was blocked. Moreover, to further confirm the effects of silicate on autophagy, a low concentration of silicate $(0.1 \mathrm{mM}$ and $0.5 \mathrm{mM})$ was used to treat the BMSCs and we analyzed the expression of LC3-II and p62 proteins via Western blot after a long-term culture of BMSCs. It was also found that there was no statistical difference in protein changes $(n=4)$, which indicated that BMSCs had good tolerance to a low concentration of silicate and the mechanism reaction was different from that of a high concentration of silicate (Additional file $2 \mathrm{~d}-\mathrm{e}$ ).
Silicate impaired autophagic flux via disrupting microtubule stability

To further confirm the reasons for the blockage of autophagic flux, the function of lysosomes, autophagosomelysosome fusion-related proteins (SNAP29, STX17, VAMP8), and microtubule stability were detected. The lyso-tracker assay, which could lock acid lysosomes, was applied to evaluate the function of lysosomes, and the Baf A1 and CQ treatment groups were set as the positive control groups. The lysosome fluorescence intensity was distinctly suppressed in the Baf A1 group compared with that of the control group $(p<0.05)$, while in the CQ and silicate $(3 \mathrm{mM})$ treatment groups, the lysosome fluorescence intensity was significantly increased compared with that of the control group; there was no statistical difference between the CQ group and silicate group (Fig. 4a, b). Moreover, the lysosome-related protein markers, including LAMP1 and LAMP2, were detected with Western blot after treatment with different concentrations of silicate $(0$, $0.1,1.5,3 \mathrm{mM})$. As shown in Fig. 4c, d, both LAMP1 and LAMP2 significantly increased in the groups treated with $1.5 \mathrm{mM}$ and $3 \mathrm{mM}$ silicate compared with that of the control group $(p<0.001$ for LAMP1, $p<0.05$ for LAMP2 in the $1.5 \mathrm{mM}$ group, $p<0.01$ for LAMP2 in the $3 \mathrm{mM}$

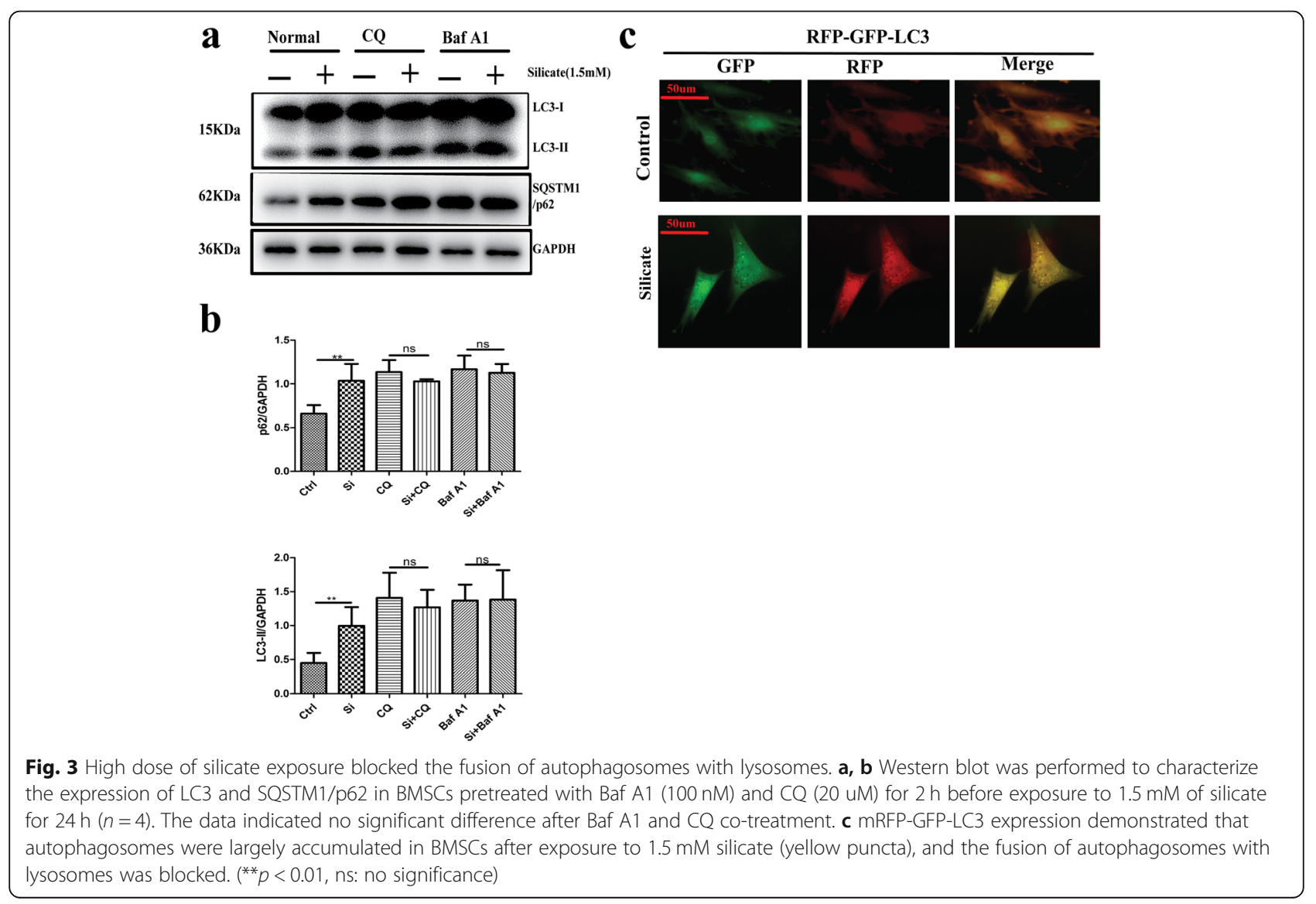




\section{a}

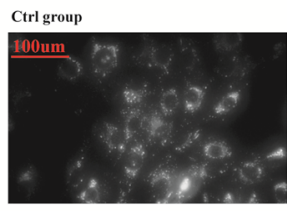

CLQ group

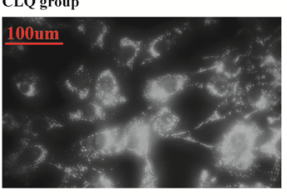

c
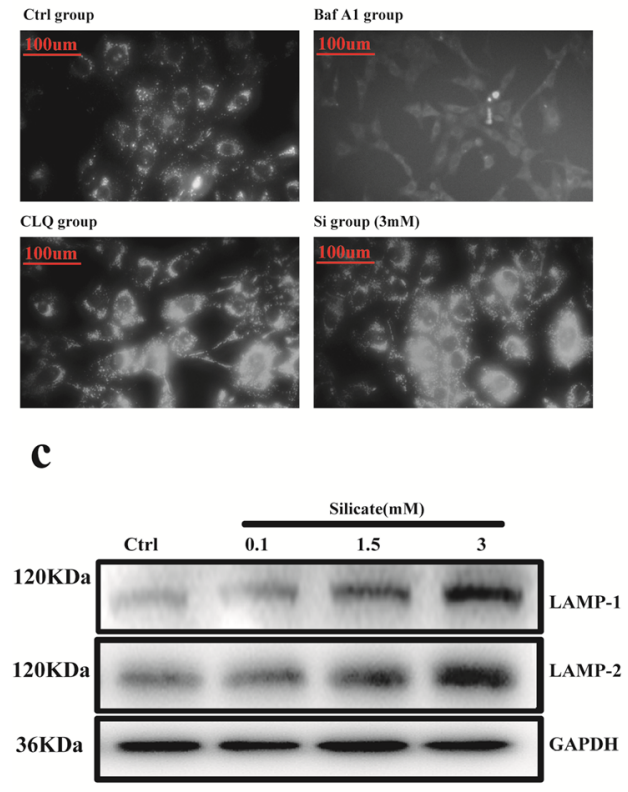

b

d
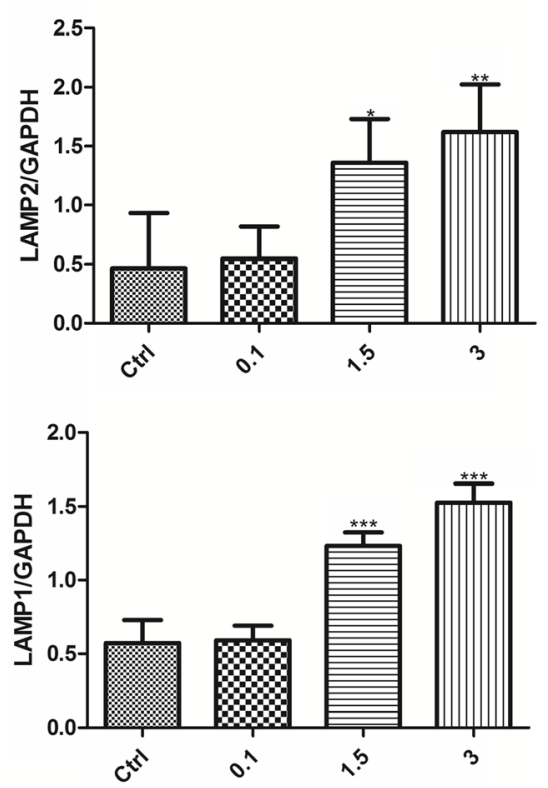

Fig. 4 High concentration of silicate did not affect lysosome function of BMSCs. a, b Lyso-tracker assay, which could lock acid lysosomes, was applied to evaluate the function of lysosomes, and the Baf A1 and CQ treatment groups were set as the positive control groups $(n=3,30$ random cells per sample). The data indicated that the fluorescence intensity in the silicate (3 mM)-treated groups was similar to that of the CQtreated group, and the intensity increased significantly compared with that of the control group. $\mathbf{c}$, $\mathbf{d}$ Western blot was performed to characterize the expression of LAMP1 and LAMP2 in BMSCs after exposure to silicate for $24 \mathrm{~h}(n=4)$. Data analysis showed that LAMP1 and LAMP2 increased significantly in the high-concentration silicate group. $\left({ }^{*} p<0.05,{ }^{* *} p<0.01,{ }^{* *} p<0.001\right)$

group). Then, autophagosome-lysosome fusion-related proteins including SNAP29, STX17, and VAMP8 were determined by Western blot and RT-qPCR. There was no statistically significant difference between the silicate group and control group in the protein expression of SNAP29, STX17, and VAMP8 after $24 \mathrm{~h}$ of exposure to different concentrations of silicate (Fig. 5a, b). Gene detection via RT-qPCR further confirmed that high-dose silicate had no significant effect on the expression of SNAP29, STX17, and VAMP8 genes (Fig. 5c). Finally, the structure of the microtubules was evaluated with a tubulin-tracker (Fig. 6a). As the concentration of silicate increased, the structure of the microtubules presented an obvious collapsed state. On the one hand, the cell volume decreased significantly; on the other hand, the microtubule lost its bundle or reticular structure, especially in the $3 \mathrm{mM}$ silicate group. Acetylated tubulin is essential for the stabilization of microtubules and facilitation of intracellular trafficking $[26,27]$; therefore, the rate of acetyl- $\alpha$ tubulin/ $\alpha$-tubulin was further detected via Western blot. As shown in Fig. 6 b, the acetyl- $\alpha$-tubulin protein was significantly downregulated after treatment with a high dose of silicate (1.5 mM and $3 \mathrm{mM}$ groups) compared with that of the control group $(p<0.001)$. Furthermore, HDAC6, a specific enzyme responsible for regulating the acetylation process of $\alpha$-tubulin [28, 29], was also evaluated via Western blot and HDAC6 activity assay. As shown in Fig. 6c, d, the expression and activity of HDAC6 in the $1.5 \mathrm{mM}$ and 


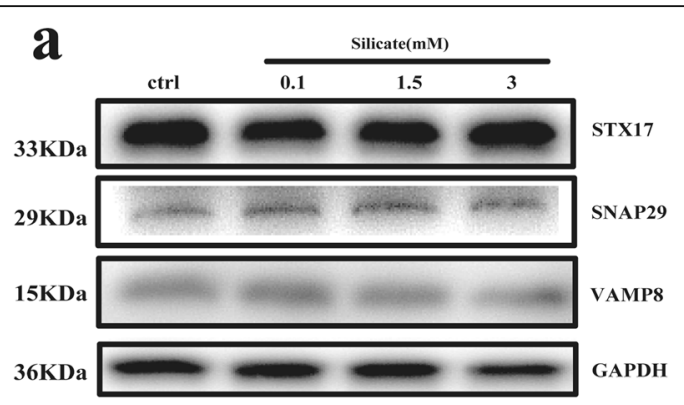

b
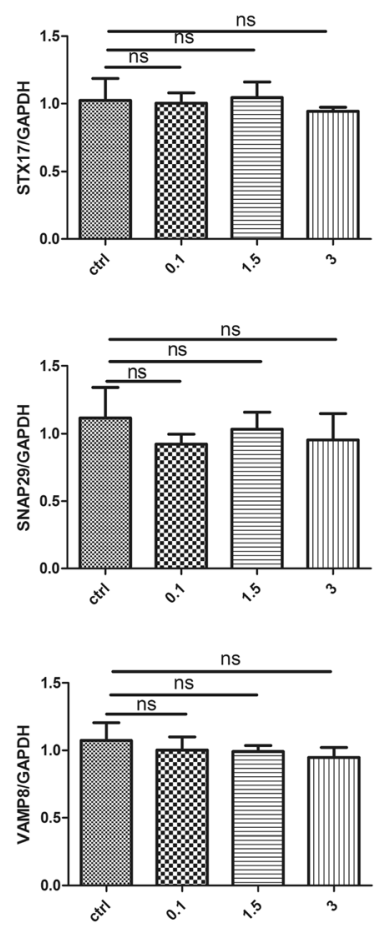

C
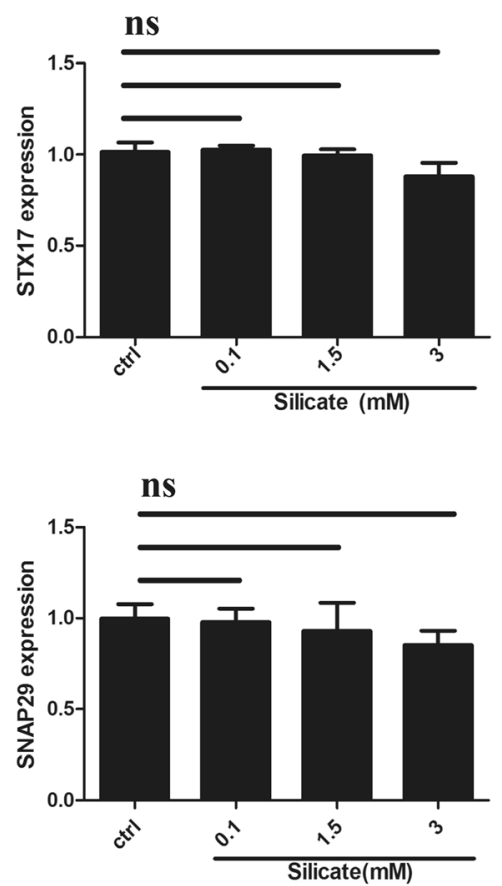

ns

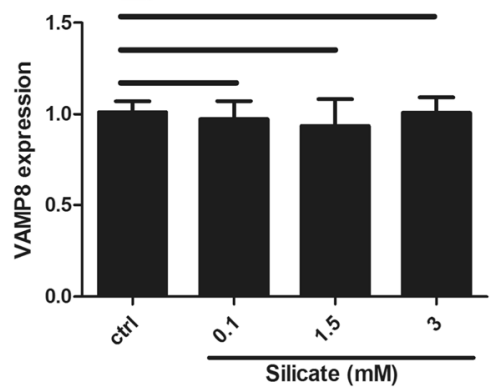

Fig. 5 High concentration of silicate did not affect the expression of autophagosome-lysosome fusion related proteins of BMSCs. $\mathbf{a}, \mathbf{b}$ Autophagosome-lysosome fusion-related proteins including SNAP29, STX17, and VAMP8 were determined by Western blot $(n=4)$. There was no significant difference after exposure to different doses of silicate for $24 \mathrm{~h}$. c RT-qPCR further confirmed that there was no significant difference in the gene expression of SNAP29, STX17, and VAMP8 between groups $(n=4)$. (ns: no significance)

$3 \mathrm{mM}$ silicate groups demonstrated a significant increase compared with that of the control group $(p<0.001)$.

\section{Inhibition of HDAC6 activity restored microtubule stability and autophagic activity}

To confirm the relationship of HDAC6 activity with microtubule stability and autophagic flux, HDAC6 expression was silenced via siHDAC6 transfection. The expression of HDAC6 mRNA declined 85.8\% (nsRNA = $50.49 \pm 13.55$ vs SiHDAC6 $=7.19 \pm 3.20$ ) when the cells were treated with $50 \mathrm{nM}$ siRNA. HDAC6 activity was significantly downregulated compared with that of the control group after transfection with siHDAC6 from Western blot detection and HDAC6 activity assay $(p<$ 0.01 ; Fig. $7 \mathrm{a}-\mathrm{c}$ ). Simultaneously, the expression of acetyl- $\alpha$-tubulin protein was detected via Western blot. As shown in Fig. 7a, b, the suppression of HDAC6 significantly increased the expression of acetyl- $\alpha$-tubulin $(p<0.01)$; moreover, the structure of the microtubules was also evaluated with a tubulin-tracker. As shown in Fig. 7d, the collapsed state of BMSCs, which was caused by high-dose silicate, was partially restored via the suppression of HDAC6. The autophagic flux-related proteins including p62 and LC3-II were identified after transfection with siHDAC6. As shown in Fig. 8a, b, the expression of p62 and LC3-II after high-dose silicate treatment was partially downregulated via HDAC6 interference compared with that of the control group $(p<$ 0.05). The immunofluorescence detection of LC3 further confirmed that autophagosome (LC3 dots) accumulation 


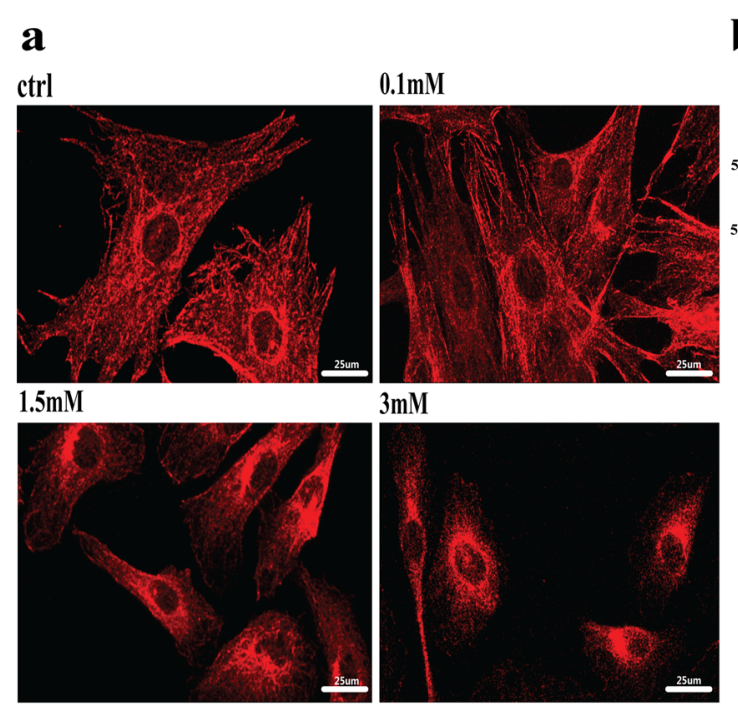

b

c
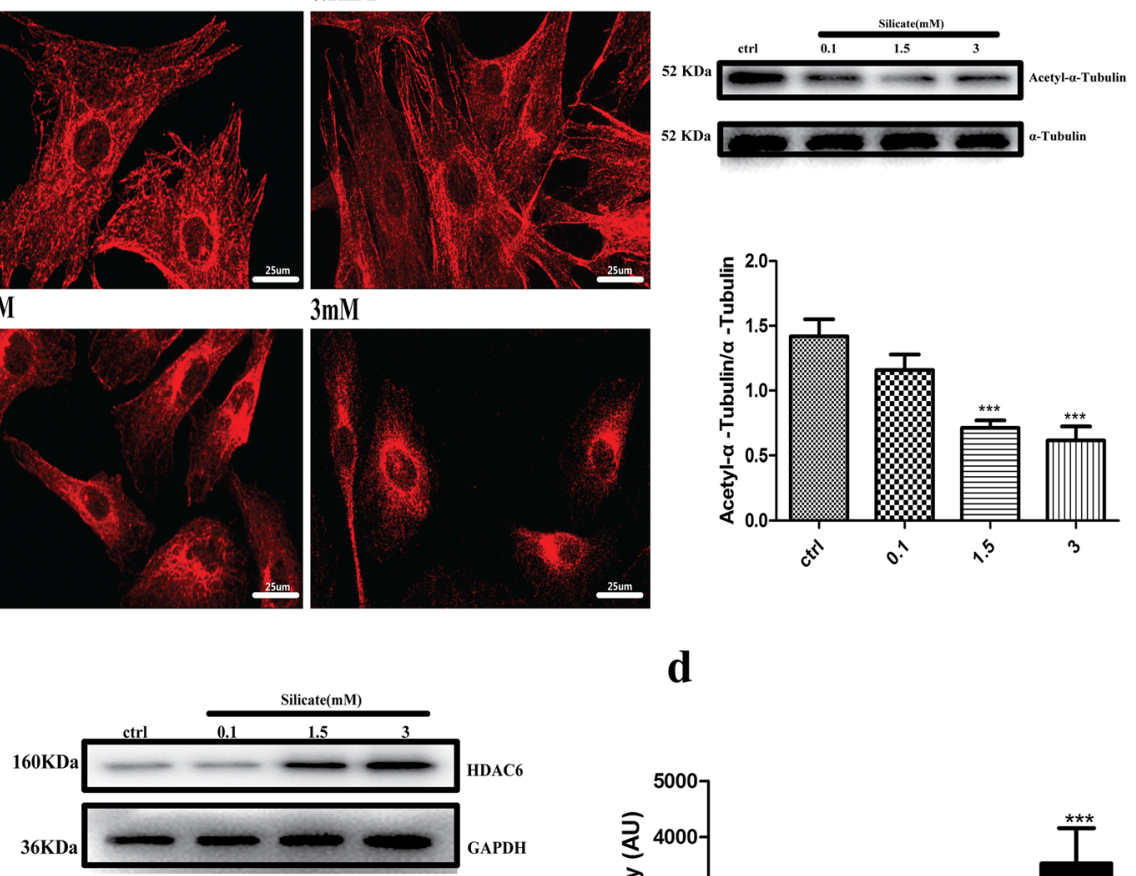

d
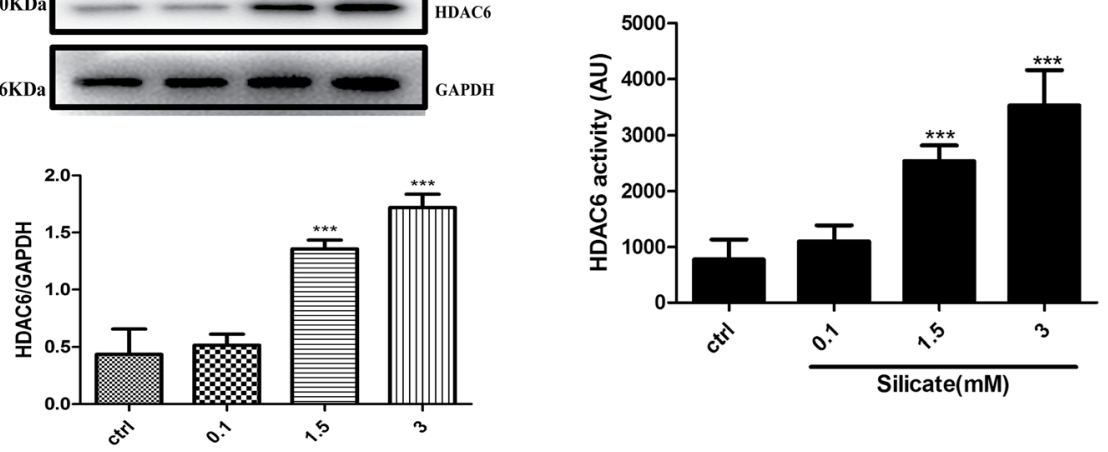

Fig. 6 Silicate impaired microtubule stability via deacetylation of a-tubulin. a The structure of microtubules was evaluated with tubulin-tracker. As the concentration of silicate increased, the structure of the microtubules presented an obvious collapsed state with cell volume decrease and loss of bundle or reticular structure. $\mathbf{b}$ Western blot showed that acetylation of a-tubulin in BMSCs was decreased after exposure to silicate for $24 \mathrm{~h}$ $(n=4)$. c, $\mathbf{d}$ HDAC6, a specific enzyme responsible for regulating the acetylation process of a-tubulin, was evaluated via Western blot and HDAC6 activity assay $(n=4)$. The data indicated that the expression and activity of HDAC6 in the $1.5 \mathrm{mM}$ and $3 \mathrm{mM}$ silicate groups demonstrated a significant increase compared with that of the control group. $\left.{ }^{* * *} p<0.001\right)$

caused by high-dose silicate was partially improved with siHDAC6 treatment $(p<0.001$; Fig. 8c, d). Furthermore, CCK- 8 assay was applied to evaluate cell viability after siHADC6 treatment. As shown in Fig. 8e, the downregulation of cell viability caused by $1.5 \mathrm{mM}$ and $3 \mathrm{mM}$ silicate was significantly improved after siHDAC6 treatment ( $p<0.05$ in the $1.5 \mathrm{mM}$ group and $p<0.001$ in the $3 \mathrm{mM}$ group).

\section{Discussion}

Bone formation mainly involves two major processes: osteogenesis and angiogenesis. BMSCs are indispensable in the process of bone formation and play an accelerative role in promoting angiogenesis [30]. Biocompatibility of biomaterials with the host microenvironment plays a crucial role in maintaining the adhesion, proliferation, and differentiation of BMSCs. Silicon is a kind of trace element in the human body and is especially important for bone growth and development [31]. Extensive studies have confirmed that silicon-based biomaterials can not only promote osteogenesis formation but also stimulate angiogenesis via BMSC interaction [4, 32]. In recent years, an increasing number of researchers have paid attention to the cytotoxic mechanisms of silicon-doped materials; whether silicon nanomaterials or high concentration of free silicate, both can affect the cell viability to some extent [33]. In this study, it was found that treating BMSCs with a high concentration of soluble silicate could affect the viability of BMSCs and cause the interruption of autophagic flux of BMSCs, and the interruption of autophagic flux was related to the destabilization of microtubule structure. Furthermore, microtubule 


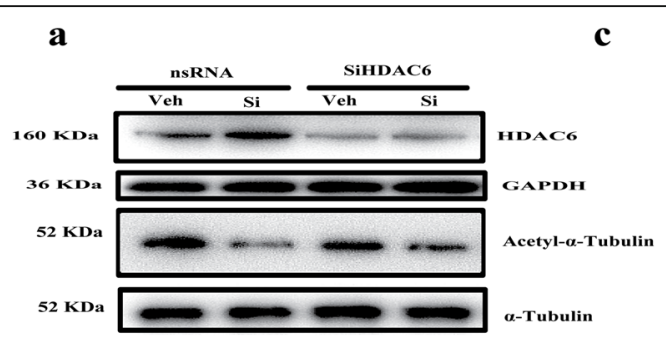

b
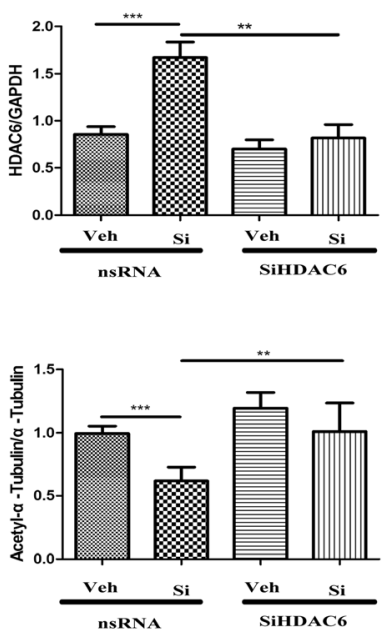

d

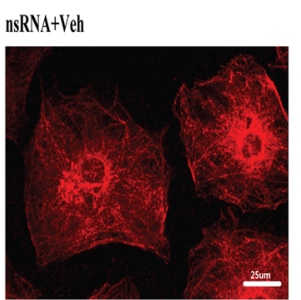

siRNAHDAC6+Veh

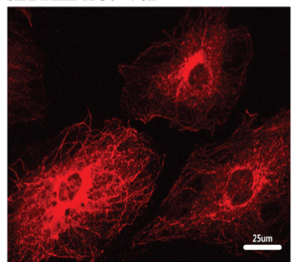

nsRNA+Si

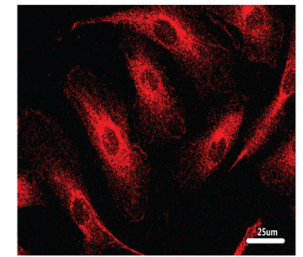

siRNAHDAC6+Si

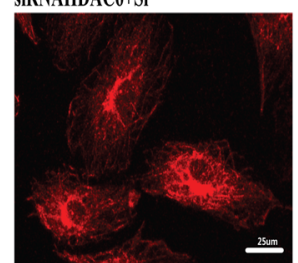

Fig. 7 Inhibition of HDAC6 activity restored microtubule stability after silicate exposure. HDAC6 expression was silenced via siHDAC6 transfection $(50 \mathrm{nM})$ and subsequently exposed to a high dose of silicate $(3 \mathrm{mM})$. $\mathbf{a}, \mathbf{b}, \mathbf{c}$ HDAC6 expression and activity were significantly downregulated compared with that of the control group after transfection with siHDAC6 from Western blot detection and HDAC6 activity assay, and the suppression of HDAC6 significantly increased the expression of acetyl-a-tubulin with Western blot detection $(n=4)$. $\mathbf{d}$ Collapsed state and bundle or reticular structure of microtubules, caused by high-dose silicate, was partially restored via the suppression of HDAC6. $\left({ }^{* *} p<0.01,{ }^{* * *} p<0.001\right)$

destabilization caused by silicate was induced by HDAC6 activation via $\alpha$-tubulin histone deacetylation.

Autophagy is a self-protective mechanism of cells under stress. The interruption of autophagic flux can further cause a large accumulation of autophagosomes, leading to an imbalance of cell homeostasis. On the one hand, damaged organelles inside cells cannot be removed, especially mitochondria and endoplasmic reticulum, which can directly trigger apoptosis; on the other hand, the interruption of the cell energy cycle leads to an energy crisis [34]. In this study, it was found that a high concentration of silicate can lead to a simultaneous increase of LC3-II and p62; LC3-II is the marker protein of autophagosomes, while p62 protein can bridge the binding of ubiquitination protein and LC3 to promote clearance of the targeted ubiquitination protein through autophagic flux; the simultaneous increase of both often indicates the interruption of autophagy flux [35]. Furthermore, we detected the LC3-II and p62 expression with LC3 turnover test via CQ and Baf A1 application. The data confirmed that a high concentration of silicate could lead to disruption of the autophagic flux
( $>1.5 \mathrm{mM})$, causing a large accumulation of autophagosomes via LC3 fluorescence detection. Accordingly, the cell viability test found that with a further increase in the high concentration of silicate, the intracellular silicon increased, and cell viability gradually decreased, suggesting that the interruption of autophagic flux may affect cell viability [36].

Autophagic flux is the process of the formation of autophagosomes within cells and eventual fusion with lysosomes. The regulation of autophagic flux involves various molecules and microstructures, among which the function of the lysosome is of vital importance and is the key point for the smooth flux of autophagy. Lysotracker is a lysosomal fluorescent probe that can selectively remain in acidic lysosomes, thus achieving specific fluorescent labeling of living cell lysosomes [37]. Our study indicated that a high concentration of silicate did not affect the acidic environment in lysosomes; moreover, CQ and Baf A1 were set as the positive control groups, and the study further confirmed that highconcentration silicate may interfere with autophagy flux in a way similar to CQ. Mauthe et al. found that the 


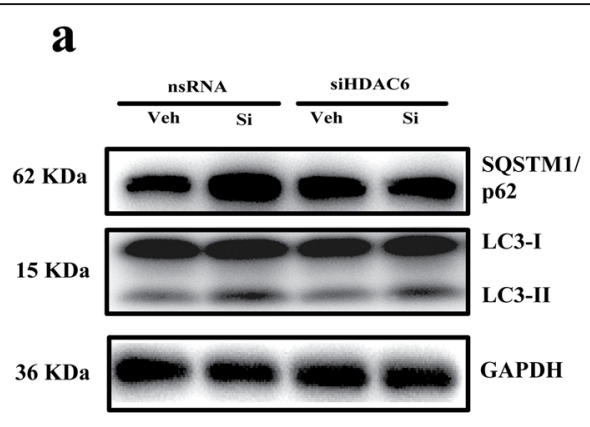

b
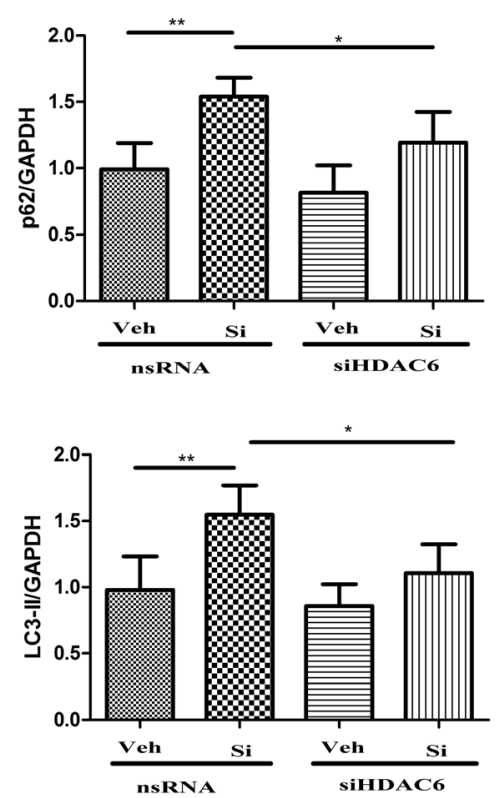

c

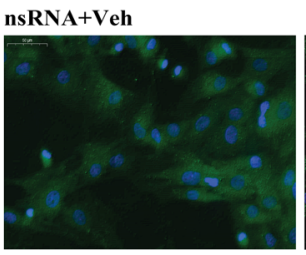

nsRNA+Si

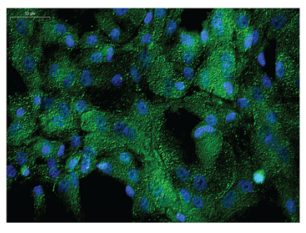

SiHDAC6+Si
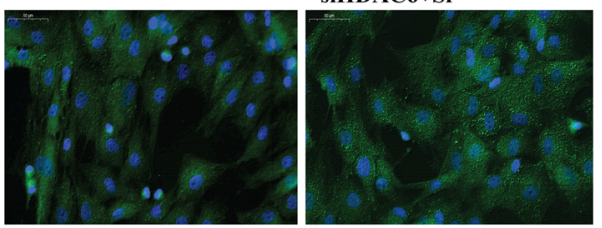

d

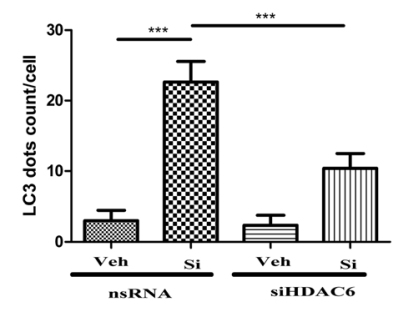

e

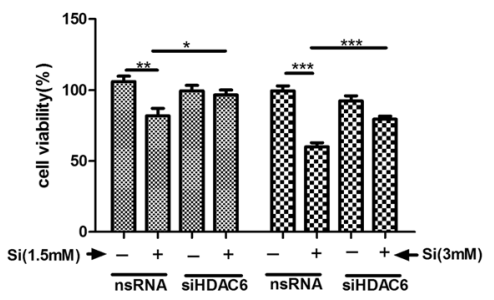

Fig. 8 Inhibition of HDAC6 activity restored autophagic activity and improved cell viability after silicate exposure. a, b Autophagic flux-related proteins including p62 and LC3-II were identified by Western blot after transfection with siHDAC6 $(n=4)$. Data analysis showed that the expression of p62 and LC3-II after high-dose silicate treatment was partially downregulated via HDAC6 interference compared with that of the control group. c, d Autophagosome (LC3 dots) accumulation caused by high-dose silicate was partially improved with siHDAC6 treatment $(n=3$, 10 random fields per sample). e CCK- 8 assay was applied to evaluate cell viability after siHADC6 treatment. As the data show, the downregulation of cell viability caused by $1.5 \mathrm{mM}$ and $3 \mathrm{mM}$ silicate was significantly improved after siHDAC6 treatment $(n=4) .\left({ }^{*} p<0.05,{ }^{* *} p<0.01,{ }^{* * *} p<0.001\right)$

autophagic flux blocking mechanism of CQ and Baf A1 may not be the same: Baf A1 blocks autophagic flux mainly by altering lysosomal function, whereas $C Q$ blocks the activity of autophagic flux by affecting membrane fusion between autophagosomes and lysosomes [38], which further suggests that a high concentration of soluble silicate may disrupt autophagic flux by affecting membrane fusion. In addition, we found that the expression of LAMP1 and LAMP2, two lysosomal membrane proteins [39], was increased after exposure to silicate. The inhibition of autophagy may promote lysosomal synthesis through a feedback mechanism that needs further research. We further investigated the protein and gene expression of membrane fusion assistance proteins including SNAP29, VAMP8, and STX17 [40]. The results showed that the silicate did not affect the expression of these proteins. However, it is still uncertain whether silicate can interfere with the protein interaction of different membrane fusion assistance proteins; this topic needs further study.

Microtubule structure plays an important role as a bridge in the combination of autophagosomes and lysosomes. In recent years, numerous studies have identified that hyperacetylation of $\alpha$-tubulin is necessary for the stimulation of autophagy. It was found that a decrease in $\alpha$-tubulin acetylation induced by an acidic environment 
inhibited autophagic activity and induced rat cardiomyocyte injury [41-43]. Wang et al. reported that rats with silicosis caused by silica solution $(50 \mathrm{mg} / \mathrm{rat}, 1 \mathrm{ml})$ via trachea instillation displayed a significant decrease in the expression of acetyl- $\alpha$-tubulin. This loss of deacetylation was associated with activation of HDAC6 [44]; thus, we further detected changes in the microtubule structure as well as hyperacetylation of $\alpha$-tubulin. We demonstrated that the microtubule structure was obviously disordered after the intervention of high-concentration silicate in BMSCs. It was found that acetyl- $\alpha$-tubulin, which maintained microtubule homeostasis, was significantly reduced, which also preliminarily suggested that a high concentration of silicate might affect the acetylation of microtubule proteins, further leading to the disintegration of microtubules and thereby blocking the trafficking of autophagosomes to lysosomes. $\alpha$-Tubulin acetylated modification was regulated by HDAC6 [45, 46], and our further research also confirmed that a high concentration of silicate can promote the expression of HDAC6. After using siRNA to interfere with HDAC6 expression, $\alpha$-tubulin acetylation was enhanced significantly compared with silicate treatment alone, and the microtubule structure was also partially recovered with more beam-like divergent structures. We then verified that autophagic flux was partially restored with reduced autophagosome accumulation via inhibiting HDAC6 expression. Simultaneously, cell viability increased significantly via HDAC6 suppression after high-dose silicate exposure, which indicated that the combination with siHDAC6 may provide a feasible way to protect BMSCs from the toxicity of high silicate exposure.

Silicate, as a representative of silicon ions, has been widely used in bone regeneration engineering. However, the concentration of silicate used in biomaterials is often several times or even hundreds of times higher than the normal range in human serum $(85-130 \mu \mathrm{g} / \mathrm{l})[13,14]$. This study, from the perspective of autophagy, redefines the safety range of silicate in biomaterials research for BMSCs. In brief, a high concentration of silicate intracell can enhance the activity of HDAC6; subsequently, microtubule depolymerized due to the reduction of acetyl- $\alpha$-tubulin, and silicate may interfere with autophagic flux activity via disturbing the stability of microtubule when the concentration exceeds $1.5 \mathrm{mM}$ (Fig. 9). Autophagy generally occurs earlier than cell apoptosis, which preliminarily suggests that the reasonable application of the autophagic flux test for biomaterials is of great importance. For BMSC-related studies, biomaterials containing silicon shall not exceed a concentration of $1.5 \mathrm{mM}$, and the autophagic flux test should be set as a reference indicator for biocompatibility and safety detection. Of course, the reasonable application range of different biomaterials or different organisms should be treated separately in vivo and in vitro, and this requires further exploration and discussion.

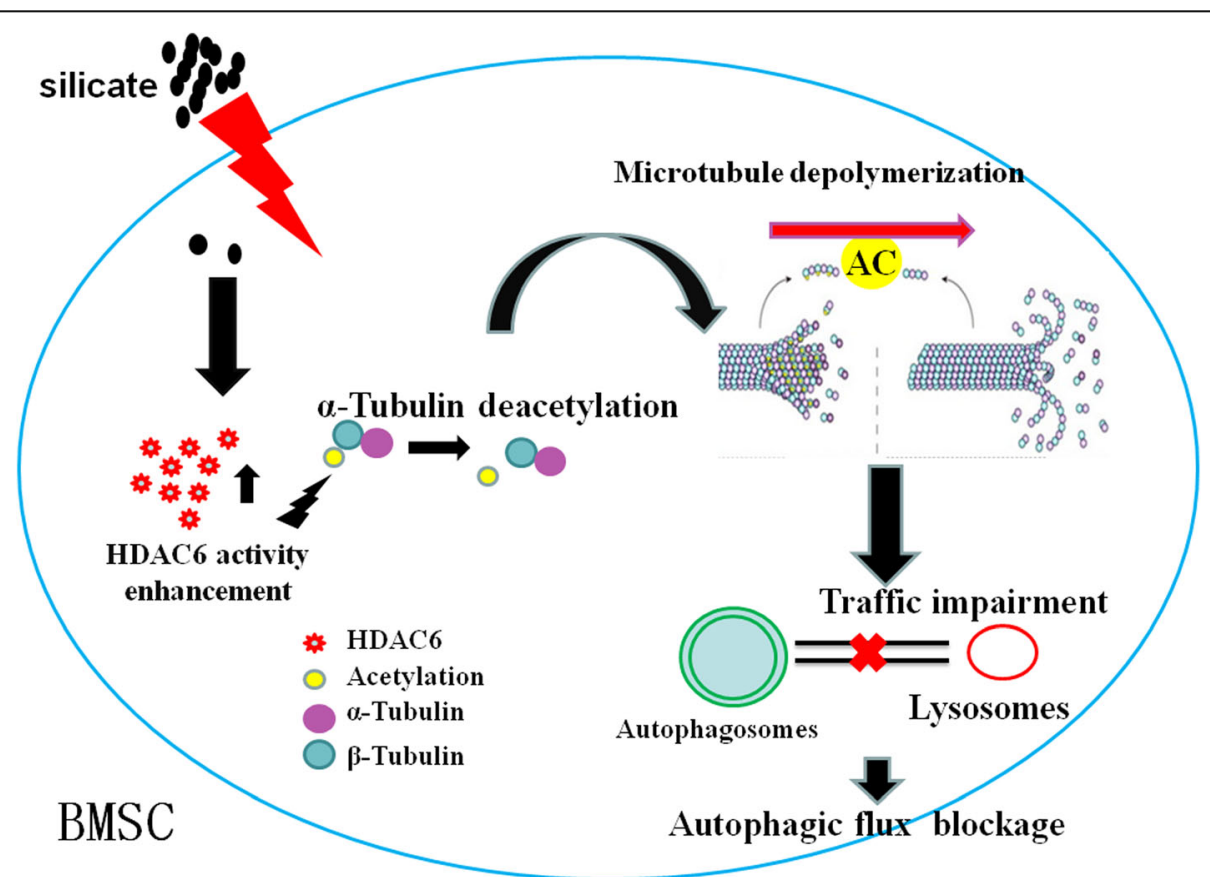

Fig. 9 Schematic diagram of silicate-induced blockage of autophagic flux. The silicate enters the BMSCs and induces the enhancement of HDAC6 activity and expression. HDAC6 further leads to the deacetylation of a-tubulin, resulting in the depolymerization of the microtubule. The autophagosomes cannot be transported to fuse with lysosomes as the microtubule disruption, which eventually leads to the blockage of autophagic flux 


\section{Conclusions}

Our study proves that a high concentration of silicate can affect the viability and cause the blockage of autophagic flux in BMSCs, and the blockage of autophagic flux was related to the destabilization of the microtubule structure. Furthermore, microtubule destabilization caused by silicate was induced by HDAC6 activation via $\alpha$-tubulin histone deacetylation. This study from the perspective of autophagy redefines the safety range of silicate in biomaterials research for BMSCs; silicate may interfere with autophagic flux activity when the concentration exceeds $1.5 \mathrm{mM}$.

\section{Supplementary information}

Supplementary information accompanies this paper at https://doi.org/10. 1186/s13287-019-1441-4.

Additional file 1. Cell viability changes after treatment with different concentrations of silicate at $6 \mathrm{~h}$ and $72 \mathrm{~h}$. (a) Cell viability decreased significantly in silicate concentration higher than $3 \mathrm{mM}$ compared with that of control group after $6 \mathrm{~h}$ exposure to silicate $(n=6)$. (b) Cell viability decreased significantly in silicate concentration higher than $1.5 \mathrm{mM}$ compared with that of control group after $72 \mathrm{~h}$ exposure to silicate $(\mathbf{n}=6)$.

Additional file 2. Cell morphologic changes and autophagic proteins expression after 3 weeks exposure to silicate. (a-c) BMSCs were treated with long-term ( 3 weeks) of $0.1 \mathrm{mM}$ and $0.5 \mathrm{mM}$ silicate. Compared with the control group, the silicate did not show obvious cytotoxicity, the cells did not float or break as they did after treatment with high concentration of silicate, and some nodular changes can be observed during the cells proliferation (Arrow). (d-e) we analyzed the expression of LC3-II and p62 proteins via western-blot after a long-term culture of BMSCs, and it was also found that there was no statistical difference in protein changes $(n=4)$.

\section{Abbreviations}

Baf A1: Bafilomycin A1; BMSCs: Bone mesenchymal stem cells;

CQ: Chloroquine; HDAC6: Histone deacetylase 6; Snap29: Synaptosome associated protein 29; STX17: Syntaxin 17; Vamp8: Vesicle-associated membrane protein 8

\section{Acknowledgements}

We appreciate the instructive suggestions of Professor Changsheng Liu and his fellows from East China University of Science and Technology.

\section{Authors' contributions}

LZ, LS, and FT conducted the experiments. PY analyzed the results and designed the figures. LZ wrote the manuscript. ZJ conceived the idea and directed the experiments. All authors read and approved the final manuscript.

\section{Funding}

This work was supported by the Key Project of Natural Science Foundation of China (Grant No. 31330028)

\section{Availability of data and materials}

Original data that support the findings of this study are available from the corresponding author upon reasonable request.

\section{Ethics approval and consent to participate}

All animals procedures were reviewed and approved by the Ethics Committee of Zhongshan Hospital affiliated to Fudan University.

\section{Consent for publication}

Not applicable.

\section{Competing interests}

The authors declare that they have no competing interests.
Received: 11 May 2019 Revised: 1 September 2019

Accepted: 3 October 2019 Published online: 27 November 2019

\section{References}

1. Li WJ, Tuli R, Huang X, Laquerriere P, Tuan RS. Multilineage differentiation of human mesenchymal stem cells in a three-dimensional nanofibrous scaffold. Biomaterials. 2005;26(25):5158-66.

2. Li D, Zhu L, Liu Y, Yin Z, Liu Y, Liu F, et al. Stable subcutaneous cartilage regeneration of bone marrow stromal cells directed by chondrocyte sheet. Acta Biomater. 2017;54:321-32.

3. Granero-Molto F, Weis JA, Miga MI, Landis B, Myers TJ, O'Rear L, et al. Regenerative effects of transplanted mesenchymal stem cells in fracture healing. Stem Cells. 2009;27(8):1887-98.

4. Li H, Xue K, Kong N, Liu K, Chang J. Silicate bioceramics enhanced vascularization and osteogenesis through stimulating interactions between endothelia cells and bone marrow stromal cells. Biomaterials. 2014;35(12): 3803-18.

5. Wu C, Chang J. A review of bioactive silicate ceramics. Biomed Mater. 2013; 8(3):32001.

6. Deng Y, Jiang C, Li C, Li T, Peng M, Wang J, et al. 3D printed scaffolds of calcium silicate-doped beta-TCP synergize with co-cultured endothelial and stromal cells to promote vascularization and bone formation. Sci Rep. 2017; 7(1):5588.

7. Huang Y, Wu C, Zhang X, Chang J, Dai K. Regulation of immune response by bioactive ions released from silicate bioceramics for bone regeneration. Acta Biomater. 2018;66:81-92.

8. Goto K, Kuroda Y, Kawai T, Kawanabe K, Matsuda S. The use of a bioactive bone cement containing apatite-wollastonite glass-ceramic filler and bisphenol-a-glycidyl methacrylate resin for acetabular fixation in total hip arthroplasty: long-term follow-up results of a clinical trial. Bone Joint J. 2019; 101-B(7):787-92.

9. Bennett C, Samikkannu M, Mohammed F, Dietrich WD, Rajguru SM, Prasad A. Blood brain barrier (BBB)-disruption in intracortical silicon microelectrode implants. Biomaterials. 2018;164:1

10. Biran R, Martin DC, Tresco PA. Neuronal cell loss accompanies the brain tissue response to chronically implanted silicon microelectrode arrays. Exp Neurol. 2005;195(1):115-26.

11. Han P, Wu C, Xiao Y. The effect of silicate ions on proliferation, osteogenic differentiation and cell signalling pathways (WNT and $\mathrm{SHH}$ ) of bone marrow stromal cells. Biomaterials Sci. 2013;1(4):379.

12. Li Z, Liu S, Cao Y, Fu T, Jiang L, Zhang J. High concentration of sodium metasilicate impairs autophagic flux and induces apoptosis in human umbilical vein endothelial cells. Biol Trace Elem Res. 2019;191:88.

13. Dashnyam K, El-Fiqi A, Buitrago JO, Perez RA, Knowles JC, Kim HW. A mini review focused on the proangiogenic role of silicate ions released from silicon-containing biomaterials. J Tissue Eng. 2017:8:1545530549.

14. Pruksa S, Siripinyanond A, Powell JJ, Jugdaohsingh R. Silicon balance in human volunteers; a pilot study to establish the variance in silicon excretion versus intake. Nutr Metab (Lond). 2014;11(1):4.

15. Ohsumi Y. Historical landmarks of autophagy research. Cell Res. 2014;24(1): 9-23.

16. Napoletano F, Baron O, Vandenabeele P, Mollereau B, Fanto M. Intersections between regulated cell death and autophagy. Trends Cell Biol. 2019;29:323.

17. Doherty J, Baehrecke EH. Life, death and autophagy. Nat Cell Biol. 2018; 20(10):1110-7

18. Ma Y, Qi M, An Y, Zhang L, Yang R, Doro DH, et al. Autophagy controls mesenchymal stem cell properties and senescence during bone aging. Aging Cell. 2018;17(1):669.

19. Zhang K, Liu F, Jin D, Guo T, Hou R, Zhang J, et al. Autophagy preserves the osteogenic ability of periodontal ligament stem cells under high glucose conditions in rats. Arch Oral Biol. 2019:101:172-9.

20. Wang J, Yu Y, Lu K, Yang M, Li Y, Zhou X, et al. Silica nanoparticles induce autophagy dysfunction via lysosomal impairment and inhibition of autophagosome degradation in hepatocytes. Int J Nanomedicine. 2017;12: 809-25.

21. Schutz I, Lopez-Hernandez T, Gao Q, Puchkov D, Jabs S, Nordmeyer D, et al. Lysosomal dysfunction caused by cellular accumulation of silica nanoparticles. J Biol Chem. 2016;291(27):14170-84.

22. Stern ST, Adiseshaiah PP, Crist RM. Autophagy and lysosomal dysfunction as emerging mechanisms of nanomaterial toxicity. Part Fibre Toxicol. 2012;9:20. 
23. Mladenovic Z, Johansson A, Willman B, Shahabi K, Bjorn E, Ransjo M. Soluble silica inhibits osteoclast formation and bone resorption in vitro. Acta Biomater. 2014;10(1):406-18.

24. Schroder HC, Wang XH, Wiens M, Diehl-Seifert B, Kropf K, Schlossmacher U, et al. Silicate modulates the cross-talk between osteoblasts (SaOS-2) and osteoclasts (RAW 264.7 cells): inhibition of osteoclast growth and differentiation. J Cell Biochem. 2012;113(10):3197-206.

25. Liu S, Liu Y, Jiang L, Li Z, Lee S, Liu C, et al. Recombinant human BMP-2 accelerates the migration of bone marrow mesenchymal stem cells via the CDC42/PAK1/LIMK1 pathway in vitro and in vivo. Biomater Sci. 2018;7(1): 362-72

26. Portran D, Schaedel L, Xu Z, Thery M, Nachury MV. Tubulin acetylation protects long-lived microtubules against mechanical ageing. Nat Cell Biol. 2017;19(4):391-8.

27. Badding MA, Dean DA. Highly acetylated tubulin permits enhanced interactions with and trafficking of plasmids along microtubules. Gene Ther. 2013;20(6):616-24

28. Hubbert C, Guardiola A, Shao R, Kawaguchi Y, Ito A, Nixon A, et al. HDAC6 is a microtubule-associated deacetylase. Nature. 2002:417(6887):455-8.

29. Li G, Jiang H, Chang M, Xie H, Hu L. HDAC6 alpha-tubulin deacetylase: a potential therapeutic target in neurodegenerative diseases. J Neurol Sci. 2011;304(1-2):1-8.

30. Bronckaers A, Hilkens P, Martens W, Gervois P, Ratajczak J, Struys T, et al. Mesenchymal stem/stromal cells as a pharmacological and therapeutic approach to accelerate angiogenesis. Pharmacol Ther. 2014; 143(2):181-96

31. Jugdaohsingh R. Silicon and bone health. J Nutr Health Aging. 2007;11(2): 99-110

32. Bunpetch V, Zhang X, Li T, Lin J, Maswikiti EP, Wu Y, et al. Silicate-based bioceramic scaffolds for dual-lineage regeneration of osteochondral defect. Biomaterials. 2019;192:323-33.

33. Asweto $\mathrm{CO}, \mathrm{Wu} J$, Alzain MA, Hu H, Andrea S, Feng L, et al. Cellular pathways involved in silica nanoparticles induced apoptosis: a systematic review of in vitro studies. Environ Toxicol Pharmacol. 2017; 56:191-7.

34. Parzych KR, Klionsky DJ. An overview of autophagy: morphology, mechanism, and regulation. Antioxid Redox Signal. 2014;20(3):460-73.

35. Boyle KB, Randow F. The role of 'eat-me' signals and autophagy cargo receptors in innate immunity. Curr Opin Microbiol. 2013;16(3): 339-48.

36. Button RW, Roberts SL, Willis TL, Hanemann CO, Luo S. Accumulation of autophagosomes confers cytotoxicity. J Biol Chem. 2017;292(33): 13599-614

37. Wu F, Xu HD, Guan JJ, Hou YS, Gu JH, Zhen XC, et al. Rotenone impairs autophagic flux and lysosomal functions in Parkinson's disease. Neuroscience. 2015;284:900-11.

38. Mauthe M, Orhon I, Rocchi C, Zhou X, Luhr M, Hijlkema KJ, et al. Chloroquine inhibits autophagic flux by decreasing autophagosomelysosome fusion. Autophagy. 2018;14(8):1435-55.

39. Eskelinen EL. Roles of LAMP-1 and LAMP-2 in lysosome biogenesis and autophagy. Mol Asp Med. 2006;27(5-6):495-502.

40. Nakamura S, Yoshimori T. New insights into autophagosome-lysosome fusion. J Cell Sci. 2017:130(7):1209-16.

41. Xie R, Nguyen S, McKeehan WL, Liu L. Acetylated microtubules are required for fusion of autophagosomes with lysosomes. BMC Cell Biol. 2010;11:89.

42. Yang L, Zhao L, Cui L, Huang Y, Ye J, Zhang Q, et al. Decreased alphatubulin acetylation induced by an acidic environment impairs autophagosome formation and leads to rat cardiomyocyte injury. J Mol Cell Cardiol. 2019;127:143-53

43. Geeraert C, Ratier A, Pfisterer SG, Perdiz D, Cantaloube I, Rouault A, et al. Starvation-induced hyperacetylation of tubulin is required for the stimulation of autophagy by nutrient deprivation. J Biol Chem. 2010;285(31): 24184-94.

44. Xiaojun W, Yan L, Hong X, Xianghong Z, Shifeng L, Dingjie X, et al. Acetylated alpha-tubulin regulated by $\mathrm{N}$-acetyl-seryl-aspartyl-lysyl-proline (ac-SDKP) exerts the anti-fibrotic effect in rat lung fibrosis induced by silica. Sci Rep. 2016:6:32257.

45. Song $R$, Yang $Y$, Lei $H$, Wang G, Huang $Y$, Xue W, et al. HDAC6 inhibition protects cardiomyocytes against doxorubicin-induced acute damage by improving alpha-tubulin acetylation. J Mol Cell Cardiol. 2018;124:58-69.

46. Asthana J, Kapoor S, Mohan R, Panda D. Inhibition of HDAC6 deacetylase activity increases its binding with microtubules and suppresses microtubule dynamic instability in MCF-7 cells. J Biol Chem. 2013;288(31):22516-26.

\section{Publisher's Note}

Springer Nature remains neutral with regard to jurisdictional claims in published maps and institutional affiliations.
Ready to submit your research? Choose BMC and benefit from:

- fast, convenient online submission

- thorough peer review by experienced researchers in your field

- rapid publication on acceptance

- support for research data, including large and complex data types

- gold Open Access which fosters wider collaboration and increased citations

- maximum visibility for your research: over $100 \mathrm{M}$ website views per year

At BMC, research is always in progress.

Learn more biomedcentral.com/submissions 